\title{
A Decision Method for Improving Tourism Industry Service Quality under Budget Constraints
}

\author{
Xiaojun Chen', Qingliang Meng', Ling Zhang2 \\ ${ }^{1}$ Department of Students Affairs, Jiangsu University of Science and Technology, Zhenjiang, China \\ ${ }^{2}$ School of Management \& Economics, Jiangsu University of Science and Technology, Zhenjiang, China \\ Email: wswkdz@foxmail.com
}

Received 9 October 2015; accepted 26 October 2015; published 29 October 2015

Copyright (C) 2015 by authors and Scientific Research Publishing Inc.

This work is licensed under the Creative Commons Attribution International License (CC BY). http://creativecommons.org/licenses/by/4.0/

c) (i) Open Access

\begin{abstract}
Based on the quantitative analysis in Kano model, this paper proposes a model for improving tourism industry service quality from customer satisfaction and cost budget constraints perspectives. Relevant evaluation information is obtained by employing the questionnaire survey and the relationships between customer satisfaction and the fulfillment of service quality elements is determined in Kano model through processing the obtained evaluation information. Then based on the relationship functions, considering the budget constraints, the optimization model of improving tourism industry service quality to maximize the customer satisfaction is constructed, and the budget allocation is determined by solving the optimization model. Finally, a case study is provided to illustrate the feasibility and availability of the proposed method.
\end{abstract}

\section{Keywords}

Service Quality, Tourism Industry, Decision Method, Kano Model

\section{Introduction}

Rapid influx of new technology and increased competition has dramatically changed the nature of business process nowadays. To hold a market leadership today, a tourism service enterprise has to put their effort into meeting customer requirements and achieving customer satisfaction to remain competitive advantages. However, the current situation is not so desirable, the complaints of tourism service quality still remain high. The achievement of the best tourism service quality must be viewed as a process of endless improvement, the factors of human features must always be taken into account when developing the market strategy and designing the 
operational processes.

Some scholars have explored the improvement of tourism service quality from different perspectives. Ting (2011) [1] provided evidence on the existing service quality problems of Three Gorges through an empirical investigation, and also provided some targeted suggestion for how to improve the tourism service quality. Wang (2012) [2] proposed a model called customer perception evaluation model based on customer tourism experience, and pointed that humanistic characteristics, time and the tourism-related are the main factors that affected customer perceptions and attitudes. Using the importance-performance analysis method, Alexandra (2012) [3] analyzed tourist service quality of Great Barrier Reef Marine park in Australia, and also provided some targeted promotion strategy. Chen (2013) [4] discussed the deterioration of travel agencies services quality, and pointed that information asymmetry was the main factor that caused service quality deterioration while travel agencies reputation can significantly improve the service quality. Above studies analyzed different methods of improving tourist service quality, they helped accurately make a more appropriate decision. Nevertheless, the role of customer has also dramatically changed from a passive buyer to value co-creator there, and also the customers set a higher request to the tourism service quality level. Thus, decision making problems of improving tourism service quality from customers' perspective should be put forward further in-depth and detailed.

Various methods and tools have been developed accordingly to help companies obtain a better understanding of customer requirements, including surveys, focus groups, individuals' interviews, creative groups' interviews, listening and watching, complaint analysis, natural field contacts, warranty data and affinity diagrams [5] [6]. Some customer requirements assessments focus on physical, quantitative product or service attributes; other assessments include subjective feelings and emotions. Although surveys commonly collect customer information, they may be affected by earlier experiences. Thus, direct surveys can produce biased responses, and their results may be misinterpreted. The Kano model has been proposed to address the limitation on assessing customer requirements. This model corrects for customer experience bias and computes the non-linear impact of service elements on customer satisfaction. Kano model is to find out the customers' affection towards products and services through questionnaire and then based on the information as references to improve the customers' satisfaction [7]. However, the model only focuses on the classification method and qualitative descriptions of various relationship curves. Limited quantitative analysis or measurement of relationships is discussed in the traditional Kano model.

Kano model is a widely used tool for understanding the voice of customers and their impact on customer satisfaction. The resources or budget of all enterprise are limited in nature, therefore, reducing costs and improving service qualities are two major strategic approaches for enterprises to stay competitive. However, enterprises must first understand what constitutes the favorite service of customers; the scare resources can then be allocated to the most cost-effective areas.

According to the lack of study on the quantitative analysis of Kano model, this paper proposes a quantitative Kano model by identifying the relationship functions between customer satisfaction and service quality elements fulfillment. Based on the quantitative analysis in Kano model, in the context of and considering cost budget, the optimization model of improving tourism industry service quality to maximize the customer satisfaction is constructed, and the budget allocation is determined by solving the optimization model.

The paper is organized as follows. In the next section, the quantitative analysis of Kano model will be described by identifying the relationship functions between customer satisfaction and quality elements fulfillment. Section 3 will propose an effective mathematical model to assign the limited budget to the most needed service items to optimize the overall service quality. An example based on tourism industry application of this method will be provided to illustrate how the proposed methodology works in practice (Section 4). Finally, a summary of the main contribution and possible future works are provided in Section 5.

\section{Review of Kano Model}

Kano et al. (1984) developed a two-dimensional model widely used to classify and prioritize customer requirements of a product or service based on how they affect customer's satisfaction. Kano model illustrates the relationship between customer satisfaction and the performance of a product or a service. Using a specific questionnaire, Kano model classified quality elements into five quality dimensions, namely, must be, one-dimensional, attractive, indifferent and reverse. In addition, there is a dimension called "questionable" that contains responses that do not make any logical sense. These quality dimensions are shown in Figure 1. As shows, the $\mathrm{x}$-axis indicates the sufficiency of a given service quality element, and the $y$-axis indicates customer satisfaction. The more 


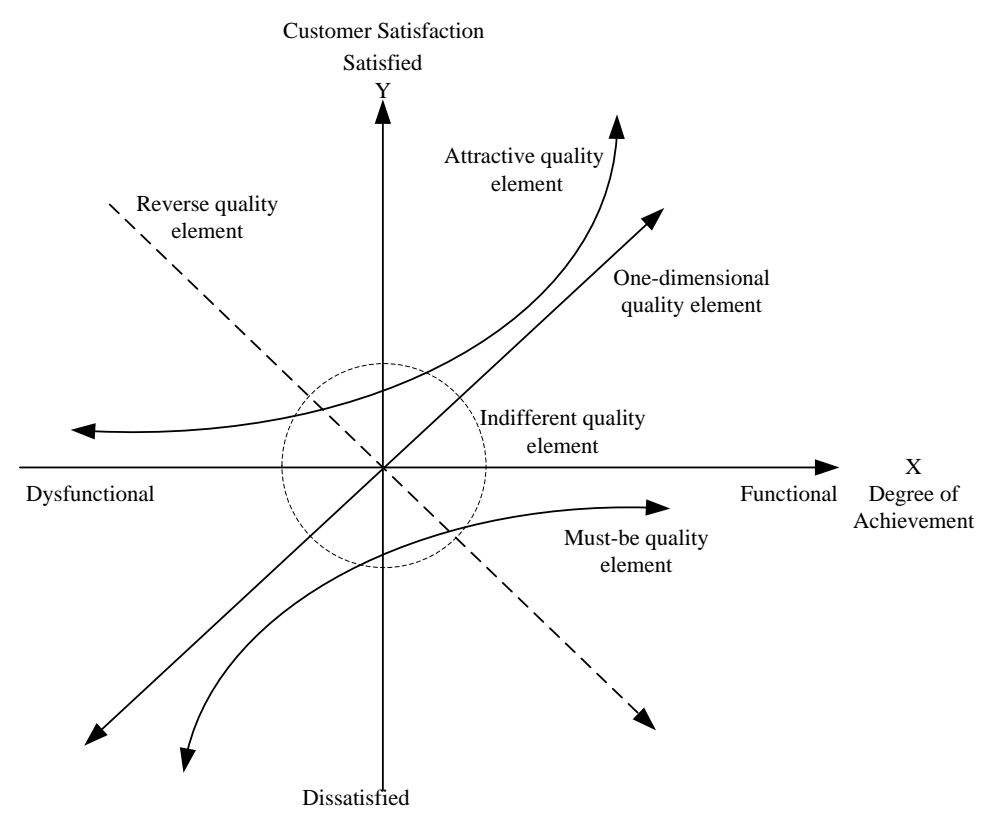

Figure 1. An overview of Kano model.

the arrow moves towards the right, the greater the extent to which the service element is provided. The more the arrow moves up, the greater the customer satisfaction.

- Must-be elements: Insufficiency of a must-be element results in extreme dissatisfaction, but basic product or service performance is enough to satisfy customer requirements. Customers take must-be elements for granted when they are fulfilled, but high element performance does not generate correspondingly high customer satisfaction.

- One-dimensional elements: A linear function relates product-element performance and customer satisfaction. The higher the level of fulfillment, the higher the degree of customer satisfaction; the reverse is also true. The customer expects these elements, and thus views them as basics.

- Attractive elements: Fulfillment of attractive elements will lead to greater than proportional satisfaction. However, the absence of these requirements does not result in dissatisfaction. These elements are usually not expected and are often currently unaware by customers. They can provide a competitive advantage.

- Indifferent elements: This element will not result in satisfaction or not, whether they are sufficient or not. This type of element is simply a product or service characteristic and not a customer requirement.

- Reverse elements: Non-satisfaction come when reverse elements are sufficient and on the contrary satisfaction come when they are insufficient. A reverse element represents an element that behaves in reverse of the performance quality.

The Kano model employs inquiring techniques with pairs of functional and dysfunctional questions about each requirement; the functional situation considers the element sufficient, while the dysfunctional situation supposes the element to be insufficient [8] [9]. As is shown in Table 1. In a Kano questionnaire, customer is required to choose one of the following responses to express their feelings: 1) I like it; 2) it must be that way; 3) I am neutral; 4) I can live with it; and 5) I dislike it. The classification is then made using an evaluation table in which customer requirement can be classified into one of five dimensions that exhibit different impacts on customer satisfaction depending on whether customer requirements are fulfilled (Table 2). From the evaluation table, Kano model classifies service quality elements into categories that exhibit different impacts on customer satisfaction depending on whether customer requirements are fulfilled. Categories are evaluated and interpreted according to the frequency of answers [10] [11].

\section{Methodology}

The decision method to maximize tourism industry service quality under budget constraints features a series of processes including elicitation, analysis, and fulfillment of service quality elements. The quantitative Kano 
Table 1. Kano questionnaire.

\begin{tabular}{|c|c|c|c|c|c|}
\hline Quality element & Like & Must be & Neutral & Live with & Dislike \\
\hline Functional & $\sqrt{ }$ & & & & \\
\hline Dysfunctional & & & & $\sqrt{ }$ & \\
\hline
\end{tabular}

Table 2. Kano evaluation table.

\begin{tabular}{|ccccccc}
\hline \multirow{2}{*}{ Quality element } & \multicolumn{3}{c}{ Dysfunctional } \\
\cline { 3 - 7 } & Like & Like & Must be & Neutral & Live with & Dislike \\
\hline \multirow{3}{*}{ Functional } & Must be & $\mathrm{Q}$ & $\mathrm{A}$ & $\mathrm{A}$ & $\mathrm{A}$ & $\mathrm{O}$ \\
& Neutral & $\mathrm{R}$ & $\mathrm{I}$ & $\mathrm{I}$ & $\mathrm{I}$ & $\mathrm{I}$ \\
& Live with & $\mathrm{R}$ & $\mathrm{I}$ & $\mathrm{I}$ & $\mathrm{I}$ & $\mathrm{M}$ \\
& Dislike & $\mathrm{R}$ & $\mathrm{I}$ & $\mathrm{I}$ & $\mathrm{R}$ & $\mathrm{M}$ \\
\end{tabular}

(Note: A: attractive; O: one-dimensional; M: must-be; I: indifferent; R: reverse; Q: questionable.)

model can assist decision-making in the process by prioritizing the service quality elements according to their impacts on the customers and producers. A nonlinear mathematical model is developed to combine the various analytical techniques.

\subsection{Identification of Service Quality Elements}

Kano model requires the survey results of customers' satisfaction using the Kano questionnaire. In general, the questionnaire is designed according to a set of customer requirements. However, the customer requirements tend to be imprecise and ambiguous due to their linguistic origins [12]. And hence it is difficult to apply analytical tools for customer requirements analysis. To allow for unambiguous understanding, the customer requirements are translated into a set of service quality elements. The distinction between customer requirements and service quality elements is in line with the domain mapping principle. Essentially, while providing customer-perceives diversity in customer requirements, the product or service producer must seek for an economy of scale in product or service fulfillment. Surveys are carried out to collect the customers' evaluation of sri according to the functional and dysfunctional forms of Kano questions. The preliminary category of service quality elements is determined using the Kano evaluation table. In this research, a set of 23 items of service quality elements are obtained.

\subsection{Division of Market Segments}

Very few products or services can be all things to all people; hence, it is important to accurately analyze a market, and then choose the appropriate segment to a target. Customers are grouped into different market segments based on their demographic and psychographic information as well as estimates of consumer purchasing power. In this research, we determine the most commonly used metrics include age, gender and income to segment market. If the division of market segments is not evident, it becomes necessary to carry out market investigations to differentiate the customer groups. Many methods and tools are available to assist the process, such as conjoint analysis, perceptual mapping, and data mining. In this research, the classification results of one market segment are presented for purpose of brevity. Of course, the other market segments can be carried out following the sample procedures.

\subsection{Quantitative Analysis of Kano Model}

Kano survey is carried out within specific market segments that consist of customers with similar demographic information. With respect to service quality elements, the Kano questionnaire is fabricated and surveys are conducted to acquire the customers' assessment of the service quality elements according to the functional and dysfunctional forms of Kano questions. However, the survey only focuses on the classification method and qualitative descriptions of various relationship curves. Limited quantitative analysis or measurement of the relationships is discussed in the model. To enhance the above aspect, a quantitative Kano model is adopted by identifying the relationships between customer satisfaction and service quality elements. 
The Kano model is constructed through customer surveys, where a customer questionnaire contains a set of question pairs for each and every product or service element. The question pair includes a functional form question, which captures the customers' response if a product or service has a certain attribute, and a dysfunctional form question, which captures the customers' response if the product or service does not have that attribute. The questionnaire is deployed to a number of customers, and each answer pair is aligned with the Kano evaluation table, revealing an individual customer's perception of a product or service attribute. The final classification of a product or service element is made based on a statistical analysis of the survey results of all respondents.

After obtaining the classification results, the proposed four-step approach is applied to quantify Kano model.

\subsubsection{Calculating CS and DS Values}

The proposed quantitative analysis of Kano model starts with calculating two important values, the extent of customer satisfaction (CS) and the extent of customer dissatisfaction (DS) [13]. Since different customers usually have different requirements and expectations, calculating $C S$ and $D S$ values can reflect the average impact of a customer requirement on the satisfaction of all customers. The letter " $f_{I}$ " in the formula bellows represents the total number of indifferent quality elements.

$$
C S_{i}=\frac{f_{A}+f_{O}}{f_{A}+f_{O}+f_{M}+f_{I}}, D S_{i}=-\frac{f_{O}+f_{M}}{f_{A}+f_{O}+f_{M}+f_{I}}
$$

\subsubsection{Determining CS and DS Points}

As Figure 1 shows, the $x$-axis indicates the sufficiency of a given service quality element, and the $y$-axis indicates customer satisfaction. In this part, we assume that if a certain quality element can be fully fulfilled, the value of $x$ is assumed to be 1 and if a certain quality element will be complete non-fulfilled, the value of $x$ is assumed to be 0 . Then the $C S$ point will be expressed as $\left(1, C S_{i}\right)$, while the $D S$ point will be expressed as $\left(0,-D S_{i}\right)$.

\subsubsection{Plotting the Relationship Curves}

After determining the $C S$ and $D S$ points, the relationship curves between customer satisfaction and service quality element fulfillment can be plotted in Figure 2. The $x$-axis represents service quality element fulfillment level ranging from 0 to 1 . The $y$-axis represents the degree of customer satisfaction or dissatisfaction ranging from -1 to 1 . For instance, the $C S$ and $D S$ points of service quality element 1 are $\left(1, C S_{1}\right)$ and $\left(0,-D S_{1}\right)$, respectively. Since service quality element 1 is an attractive attribute, its relationship curve therefore follows the shape of an exponential curve that passes its CS and DS points. Using a similar approach, the relationship curves for one-dimensional and must-be quality elements are also plotted.

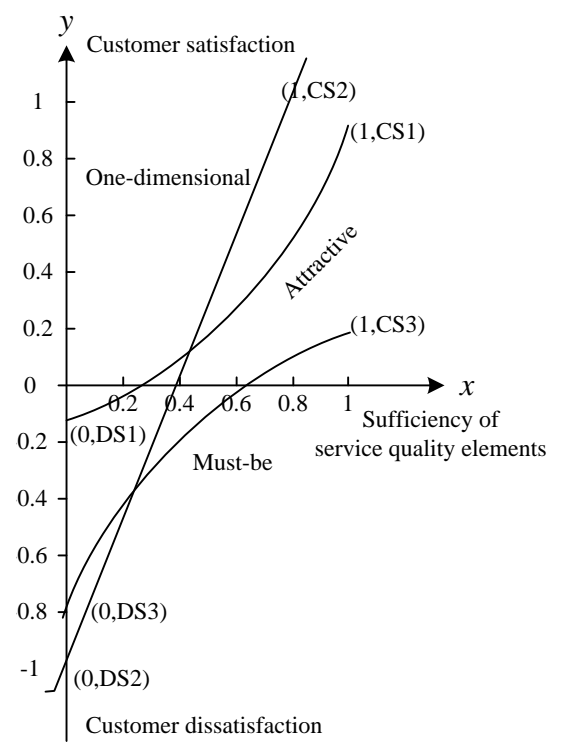

Figure 2. Relationship curves between customer satisfaction and service quality elements fulfillment. 


\subsubsection{Identifying Relationship Functions}

From the above diagram, it can be seen that the relationships between customer satisfaction and service quality elements fulfillment can be approximately quantized by an appropriate function. Generally speaking, the relationship function can be expressed as $S=f(x, a, b)$, where $S$ denotes the degree of customer satisfaction, $x$ denotes the fulfillment level of service quality elements ranging from 0 to 1 , and $a$ and $b$ are adjustment parameters for different Kano categories of service quality elements.

1) One-dimensional quality elements

Regarding the one-dimensional quality elements, the relationship curve can be expressed as $S=a_{1} x+b_{1}$, substituting $\left(1, C S_{i}\right)$ and $\left(0, D S_{i}\right)$ into the equation, it gives that $a_{1}=C S_{i}+D S_{i}$ and $b_{1}=D S_{i}$ Therefore, the function for one-dimensional quality elements is:

$$
S_{o i}=\left(C S_{i}-D S_{i}\right) x_{o i}+D S_{i}
$$

2) Attractive quality elements

Regarding the attractive quality elements, the relationship curve can be expressed as $S=a_{2} e^{x}+b_{2}$, substituting $\left(1, C S_{i}\right)$ and $\left(0, D S_{i}\right)$ into the equation, it gives that $a_{2}=\left(C S_{i}-D S_{i}\right) /(e-1)$ and $b_{2}=-\left(C S_{i}-e D S_{i}\right) /(e-1)$. Therefore, the function for attractive quality elements is:

$$
S_{a i}=\frac{C S_{i}-D S_{i}}{e-1} e^{x_{a i}}-\frac{C S_{i}-e D S_{i}}{e-1}
$$

3) Must-be quality elements

Regarding the must-be quality elements, the relationship curve can be expressed as $S=-a_{3} e^{-x}+b_{3}$, substituting $\left(1, C S_{i}\right)$ and $\left(0, D S_{i}\right)$ into the equation, it gives that $a_{3}=\frac{e\left(C S_{i}-D S_{i}\right)}{e-1}, b_{3}=\frac{e C S_{i}-D S_{i}}{e-1}$. Therefore, the function for must-be quality elements is:

$$
S_{m i}=-\frac{e\left(C S_{i}-D S_{i}\right)}{e-1} e^{-x_{m i}}+\frac{e C S_{i}-D S_{i}}{e-1}
$$

\subsection{Decision Model Formulation}

Based on the relationship function, we can calculate increased satisfaction or decreased dissatisfaction when the sufficiency provided by $x$ from level $a$ to level $b$ resulting from one unit of monetary investment.

1) One-dimensional quality elements

Regarding the one-dimensional quality elements, the relationship curve can be expressed as $S=a_{1} x+b_{1}$, when the sufficiency provided by $x$ from level $a$ to level $b$ resulting from one unit of monetary investment, the increased satisfaction is the area $A_{o}$ surrounded by points $a, b, a^{\prime}, b^{\prime}$, and the area can be computed as:

$$
A_{o}=\int_{a}^{b}\left[\left(C S_{i}-D S_{i}\right) x_{o i}+D S_{i}\right] \mathrm{d} x_{o i}
$$

where $A_{o}$ is increased customer satisfaction. If a enterprise provides $n$ one-dimensional elements, and if the sufficiency provided by each $x_{o}$ increases from $a_{i}$ to $b_{i}$, then the level of satisfaction increased by $n$ one-dimensional elements can be expressed as

$$
T A_{o}=\sum_{i=1}^{n} A_{o i}=\sum_{i=1}^{n} \int_{a_{i}}^{b_{i}}\left[\left(C S_{i}-D S_{i}\right) x_{o i}+D S_{i}\right] \mathrm{d} x_{o i}, \quad i=1,2, \cdots, n
$$

where $T A_{o}$ represents the increase of customer satisfaction. For the ease of demonstration, it is assumed that $a_{1}=a_{2}=\cdots=a_{n}=a, \quad b_{1}=b_{2}=\cdots=b_{n}=b$, the total increased satisfaction $T A_{o}$ provided by $n$ one-dimensional elements can be simplified as

$$
T A_{o}=\sum_{i=1}^{n} \int_{a}^{b}\left[\left(C S_{i}-D S_{i}\right) x_{o i}+D S_{i}\right] \mathrm{d} x_{o i}
$$


2) Attractive quality elements

Regarding the attractive quality elements, the relationship curve can be expressed as $S_{a i}=\frac{C S_{i}-D S_{i}}{e-1} e^{x_{a i}}-\frac{C S_{i}-e D S_{i}}{e-1}$, when the sufficiency provided by $x$ from level $c$ to level $d$ resulting from one unit of monetary investment, the increased satisfaction is the area $A_{a}$ surrounded by points $c, d, c^{\prime}, d^{\prime}$, and the area can be computed as:

$$
A_{a}=\int_{c}^{d}\left(\frac{C S_{i}-D S_{i}}{e-1} e^{x_{a i}}-\frac{C S_{i}-e D S_{i}}{e-1}\right) \mathrm{d} x_{a i}
$$

where $A_{a}$ is increased customer satisfaction. If a enterprise provides $n$ attractive quality elements, and if the sufficiency provided by each $x_{a}$ increases from $c_{i}$ to $d_{i}$, then the level of satisfaction increased by $n$ attractive quality elements can be expressed as

$$
T A_{a}=\sum_{i=1}^{n} A_{a}=\sum_{i=1}^{n} \int_{c_{i}}^{d_{i}}\left(\frac{C S_{i}-D S_{i}}{e-1} e^{x_{a i}}-\frac{C S_{i}-e D S_{i}}{e-1}\right) \mathrm{d} x_{a i}, \quad i=1,2, \cdots, n
$$

where $T A_{a}$ represents the increase of customer satisfaction. For the ease of demonstration, it is assumed that $c_{1}=c_{2}=\cdots=c_{n}=c, \quad d_{1}=d_{2}=\cdots=d_{n}=d$, the total increased satisfaction $T A_{a}$ provided by $n$ attractive quality elements can be simplified as:

$$
T A_{a}=\sum_{i=1}^{n} \int_{c}^{d}\left(\frac{C S_{i}-D S_{i}}{e-1} e^{x_{a i}}-\frac{C S_{i}-e D S_{i}}{e-1}\right) \mathrm{d} x_{a i}
$$

3) Must-be quality elements

Regarding the must-be quality elements, the relationship curve can be expressed as

$S_{m i}=-\frac{e\left(C S_{i}-D S_{i}\right)}{e-1} e^{-x_{m i}}+\frac{e C S_{i}-D S_{i}}{e-1}$, when the sufficiency provided by $x$ from level $e$ to level $f$ resulting from one unit of monetary investment, the decreased dissatisfaction is the area $A_{m}$ surrounded by points $e, f, e^{\prime}$, $f^{\prime}$, and the area can be computed as:

$$
A_{m}=\int_{e}^{f}\left(-\frac{e\left(C S_{i}-D S_{i}\right)}{e-1} e^{-x_{m i}}+\frac{e C S_{i}-D S_{i}}{e-1}\right) \mathrm{d} x_{m i}
$$

where $A_{m}$ is the decreased customer dissatisfaction. If a enterprise provides $n$ must-be quality elements, and if the sufficiency provided by each $x_{m}$ increases from $e_{i}$ to $f_{i}$, then the level of dissatisfaction decreased by $n$ must-be quality elements can be expressed as:

$$
T A_{m}=\sum_{i=1}^{n} A_{m}=\sum_{i=1}^{n} \int_{e_{i}}^{f_{i}}\left(-\frac{e\left(C S_{i}-D S_{i}\right)}{e-1} e^{-x_{m i}}+\frac{e C S_{i}-D S_{i}}{e-1}\right) \mathrm{d} x_{m i}, \quad i=1,2, \cdots, n
$$

where $T A_{m}$ represents the decrease of customer dissatisfaction. For the ease of demonstration, it is assumed that $e_{1}=e_{2}=\cdots=e_{n}=e, \quad f_{1}=f_{2}=\cdots=f_{n}=f$, the total decreased dissatisfaction $T A_{m}$ provided by $n$ must-be quality elements can be simplified as

$$
T A_{m}=\sum_{i=1}^{n} \int_{e}^{f}\left(-\frac{e\left(C S_{i}-D S_{i}\right)}{e-1} e^{-\chi_{m i}}+\frac{e C S_{i}-D S_{i}}{e-1}\right) \mathrm{d} x_{m i}
$$

It is known that satisfaction improvement resulting from investment in one-dimensional, attractive and must be quality elements are certainly different. Therefore, the problem is how to appropriately allocate scarce budget to the three elements in order to maximize the overall customer satisfaction. Therefore, the following equation can be formulated. 


$$
\begin{array}{ll}
\text { Model : } & \max C_{o}\left(T A_{o}\right)+C_{a}\left(T A_{a}\right)+C_{m}\left(T A_{m}\right) \\
\text { s.t. } \quad & \left\{\begin{array}{l}
C_{o}+C_{a}+C_{m} \leq B \\
0 \leq C_{o} \leq B \\
0 \leq C_{a} \leq B \\
0 \leq C_{m} \leq B \\
C_{o}=k_{1}(b-a) \\
C_{a}=k_{2}(d-c) \\
C_{m}=k_{3}(f-e) \\
0 \leq a \leq b \leq D \leq 1 \\
0 \leq c \leq d \leq E \leq 1 \\
0 \leq e \leq f \leq F \leq 1
\end{array}\right.
\end{array}
$$

$T A_{o}, T A_{a}$ and $T A_{m}$ are the improvement of customer sufficiency obtained from one unit of monetary investment, and $C_{o}, C_{a}, C_{m}$ stand for the individual budget allocated to one-dimensional quality elements, attractive quality elements and must-be quality elements, summation of the three with each multiplied by the amount of investment will become the overall customer satisfaction improvement. The " $B$ " in the above equation is the budget used to promote the overall service quality, constraints one to four must be met. When budgeted, $C_{o}$ can be improved from $a$ to $b$ with $D$ being the upper limit. When budgeted, $C_{a}$ can be improved from $c$ to $d$ with $E$ being the upper limit. When budgeted, $C_{m}$ can be improved from $e$ to $f$ with $F$ being the upper limit. The coefficients of $k_{1}, k_{2}$ and $k_{3}$ stand for the relation between budget allocated and the improvement of quality level.

The nonlinear mathematical model is solved by Lingo, and the results are obtained by solving the optimization model.

\section{Empirical Study}

To demonstrate the performance of the proposed method, an empirical study in tourism industry is given in this section. The Kano questionnaire used in this survey is shown in Table 1, including both the functional and dysfunctional forms. The questionnaire focuses on a set of 23 items of service quality elements, and the form of each item presented is shown in Table 3. A total of 150 customers constituted the Kano survey respondent set. Each customer was required to answer the Kano questions with respect to each and every service quality element. The questionnaire is distributed in the way of face-to-face. Form April 1 through May 30, 2013, 150 copies have been issued and 103copies of effective retrieved (68.7\%).

In this paper, the respondents were divided into three groups based on their age, gender, and income levels, representing three market segments as shown in Table 4. Based on the market segments, this tourism industry identifies its target customers, and finally selects market segment 2 as an accurate market. Of course, the other market segments can be carried out following the sample procedures.

Using the traditional Kano method and category definition discussed earlier, the survey results are obtained and summarized in Table 5. According to survey results, short hotel check-in time, short hotel check-in time, comfortable dining environment and appetizing food, comfortable dining environment and appetizing food, distribute the scenic panorama and brochures, distribute the scenic panorama and brochures, public telephones provided, public telephones provided, clear and sufficient road signs and facilities signs, friendly and professional service provided by tourist guide and informs the correlation matters needing attention, are classified as indifferent attributes. Therefore, they will not be included in the further analysis of Kano model in the following sections due to their little impact on customer satisfaction.

Firstly, CS and DS points are determined for each service quality element as shown in the first two columns of Table 6. Based on the final Kano classification in Table 4, suitable equations are then selected to calculate the values of $a, b$ and to determine the basic function for each service quality elements. In this way, all the functions are obtained in the last column of Table 6.

Assuming the budget for quality improvement is 1 million yuan, then the following inequality must be hold, $0 \leq$ $C_{o} \leq 100,0 \leq C_{a} \leq 100,0 \leq C_{m} \leq 100$. Besides, when $k_{1}=150, k_{2}=300, k_{3}=100$ and set $a=0.55, c=0.55, e=$ 0.55 whereas $D=0.9, E=0.8, F=1$, then the mathematical model composed of the $T A_{o}, T A_{a}$ and $T A_{m}$ becomes: 
Table 3. Tourism service quality elements and benefits provided.

\begin{tabular}{|c|c|c|}
\hline Service quality elements & Description of service elements & Benefits provided \\
\hline$f_{1}$ & Short hotel check-in time & Speediness \\
\hline$f_{2}$ & Well-equipped facilities in hotel & Pleasure, Convenience \\
\hline$f_{3}$ & Comfortable dining environment and appetizing food & Comfortable, Pleasure \\
\hline$f_{4}$ & Short waiting time in restaurant & Speediness \\
\hline$f_{5}$ & Safe and fast transportation & Safety, Speediness \\
\hline$f_{6}$ & Pay for the items damage as the rated price & Added value, Safety \\
\hline$f_{7}$ & Buy tourists the life accident insurance & Added value, Safety \\
\hline$f_{8}$ & Distribute the scenic panorama and brochures & Pleasure, Convenience \\
\hline$f_{9}$ & Reasonable ticket fee & Pleasure \\
\hline$f_{10}$ & Reasonable dining shopping fee & Pleasure \\
\hline$f_{11}$ & Safety of public security & Safety \\
\hline$f_{12}$ & Safety of tourist facilities & Safety \\
\hline$f_{13}$ & Convenient traffic & Pleasure, Convenience \\
\hline$f_{14}$ & Public telephones provided & Convenience, Added value \\
\hline$f_{15}$ & Comprehensive network coverage & Convenience, Added value \\
\hline$f_{16}$ & Clear and sufficient road signs and facilities signs & Pleasure, Convenience \\
\hline$f_{17}$ & Enough opening time & Pleasure \\
\hline$f_{18}$ & Appropriate tour route arrangement & Convenience, Speediness \\
\hline$f_{19}$ & tourist souvenirs provided & Convenience, Speediness \\
\hline$f_{20}$ & Friendly and professional service provided by tourist guide & Pleasure, Convenience \\
\hline$f_{21}$ & Tourist guide is familiar with every interests & Pleasure, Safety \\
\hline$f_{22}$ & Informs the correlation matters needing attention & Pleasure, Safety \\
\hline$f_{23}$ & Communicate smoothly with tourist guide & Pleasure, Convenience \\
\hline
\end{tabular}

\section{Table 4. Customer groups in Kano survey.}

\begin{tabular}{cccc} 
Market segment & Age & Gender & Income(10 $¥ /$ year) \\
Segment 1 & $46+$ & $\mathrm{M} / \mathrm{F}$ & 12 \\
Segment 2 & $31-45$ & $\mathrm{M} / \mathrm{F}$ & $6-11.9$ \\
Segment 3 & $21-30$ & $\mathrm{M} / \mathrm{F}$ & $3-5.9$ \\
\hline
\end{tabular}

Table 5. Results of Kano questionnaire.

\begin{tabular}{|c|c|c|c|c|c|c|c|c|c|c|}
\hline Service quality elements & $O$ & $A$ & $M$ & $I$ & $R$ & $Q$ & Total & Kano category & CS & $D S$ \\
\hline$f_{1}$ & 11 & 40 & 5 & 47 & 0 & 0 & 103 & $I$ & 0.50 & -0.16 \\
\hline$f_{2}$ & 16 & 41 & 7 & 39 & 0 & 0 & 103 & $I$ & 0.55 & -0.22 \\
\hline$f_{3}$ & 8 & 29 & 14 & 51 & 1 & 0 & 103 & $I$ & 0.36 & -0.22 \\
\hline$f_{4}$ & 16 & 31 & 7 & 49 & 0 & 0 & 103 & $I$ & 0.46 & -0.22 \\
\hline$f_{5}$ & 7 & 21 & 44 & 25 & 6 & 0 & 103 & $M$ & 0.29 & -0.53 \\
\hline$f_{6}$ & 27 & 43 & 12 & 21 & 0 & 0 & 103 & $A$ & 0.68 & -0.38 \\
\hline$f_{7}$ & 22 & 50 & 9 & 22 & 0 & 0 & 103 & $A$ & 0.70 & -0.30 \\
\hline$f_{8}$ & 19 & 12 & 23 & 48 & 1 & 0 & 103 & $I$ & 0.30 & -0.41 \\
\hline$f_{9}$ & 51 & 18 & 25 & 9 & 0 & 0 & 103 & $O$ & 0.67 & -0.74 \\
\hline$f_{10}$ & 7 & 22 & 3 & 64 & 6 & 1 & 103 & $I$ & 0.30 & -0.10 \\
\hline$f_{11}$ & 55 & 16 & 18 & 14 & 0 & 0 & 103 & $O$ & 0.69 & -0.71 \\
\hline
\end{tabular}




\section{Continued}

$\begin{array}{lllllllllll}f_{12} & 22 & 42 & 11 & 28 & 0 & 0 & 103 & A & 0.62 & -0.32 \\ f_{13} & 43 & 26 & 17 & 17 & 0 & 0 & 103 & O & 0.67 & -0.58 \\ f_{14} & 12 & 16 & 13 & 57 & 4 & 1 & 103 & I & 0.29 & -0.26 \\ f_{15} & 25 & 26 & 11 & 41 & 0 & 0 & 103 & I & 0.50 & -0.35 \\ f_{16} & 11 & 32 & 11 & 49 & 0 & 0 & 103 & I & 0.42 & -0.21 \\ f_{17} & 15 & 21 & 50 & 17 & 0 & 0 & 103 & M & 0.35 & -0.63 \\ f_{18} & 14 & 19 & 49 & 21 & 0 & 0 & 103 & M & 0.32 & -0.61 \\ f_{19} & 17 & 46 & 9 & 31 & 0 & 0 & 103 & A & 0.61 & -0.25 \\ f_{20} & 17 & 28 & 8 & 50 & 0 & 0 & 103 & I & 0.44 & -0.24 \\ f_{21} & 49 & 16 & 19 & 19 & 0 & 0 & 103 & O & 0.63 & -0.66 \\ f_{22} & 23 & 29 & 11 & 40 & 0 & 0 & 103 & I & 0.50 & -0.33 \\ f_{23} & 24 & 20 & 45 & 14 & 0 & 0 & 103 & M & 0.43 & -0.67\end{array}$

Table 6. Functions for service quality elements.

\begin{tabular}{ccccccc}
\hline Service quality elements & $C S$ points & $D S$ points & $a$ & $b$ & $f(x)$ & $S=a f(x)+b$ \\
\hline One-dimensional & & & & & & \\
\hline$f_{9}$ & $(1,0.67)$ & $(0,-0.74)$ & 1.41 & -0.74 & $x$ & $S=1.41 x-0.74$ \\
$f_{11}$ & $(1,0.69)$ & $(0,-0.71)$ & 1.40 & -0.71 & $x$ & $S=1.40 x-0.71$ \\
$f_{13}$ & $(1,0.67)$ & $(0,-0.58)$ & 1.25 & -0.58 & $x$ & $S=1.25 x-0.58$ \\
$f_{21}$ & $(1,0.63)$ & $(0,-0.66)$ & 1.29 & -0.66 & $x$ & $S=1.29 x-0.66$ \\
\hline Attractive & & & & & \\
\hline$f_{6}$ & $(1,0.68)$ & $(0,-0.38)$ & 0.62 & -1.00 & $e^{x}$ & $S=0.62 e^{x}-1.00$ \\
$f_{7}$ & $(1,0.70)$ & $(0,-0.30)$ & 0.58 & -0.88 & $e^{x}$ & $S=0.58 e^{x}-0.88$ \\
$f_{19}$ & $(1,0.62)$ & $(0,-0.32)$ & 0.55 & -0.87 & $e^{x}$ & $S=0.55 e^{x}-0.87$ \\
$f_{23}$ & $(1,0.61)$ & $(0,-0.25)$ & 0.50 & -0.75 & $e^{x}$ & $S=0.50 e^{x}-0.75$ \\
\hline Must be & & & & & \\
\hline$f_{5}$ & $(1,0.29)$ & $(0,-0.53)$ & 1.30 & 0.77 & $-e^{-x}$ & $S=-1.30 e^{-x}+0.77$ \\
$f_{12}$ & $(1,0.35)$ & $(0,-0.63)$ & 1.55 & 0.92 & $-e^{-x}$ & $S=-1.55 e^{-x}+0.92$ \\
$f_{17}$ & $(1,0.32)$ & $(0,-0.61)$ & 1.47 & 0.86 & $-e^{-x}$ & $S=-1.47 e^{-x}+0.86$ \\
$f_{18}$ & $(1,0.43)$ & $(0,-0.67)$ & 1.74 & 1.07 & $-e^{-x}$ & $S=-1.74 e^{-x}+1.07$ \\
\hline
\end{tabular}

Model : $\max C_{o}\left(T A_{o}\right)+C_{a}\left(T A_{a}\right)+C_{m}\left(T A_{m}\right)$

$$
\text { s.t. }\left\{\begin{array}{l}
C_{o}+C_{a}+C_{m} \leq 100 \\
0 \leq C_{o} \leq 100 \\
0 \leq C_{a} \leq 100 \\
0 \leq C_{m} \leq 100 \\
C_{o}=150(b-0.55) \\
C_{a}=300(d-0.55) \\
C_{m}=100(f-0.55) \\
0.55 \leq b \leq 0.9 \\
0.55 \leq d \leq 0.8 \\
0.55 \leq f \leq 1.0 \\
T A_{o}=2.675 b^{2}-2.69 b+0.6703 \\
T A_{a}=2.25 e^{d}-3.5 d-1.9748 \\
T A_{m}=6.06 e^{-f}+3.62 f-5.4873
\end{array}\right.
$$


The nonlinear mathematical model is solved by Lingo 11.0, and the results are obtained as $C_{o}=0.00742, C_{a}=$ 54.99258, $C_{m}=45$, in other words, $T A_{o}=0, T A_{a}=0.143, T A_{m}=0.362$, and the overall customer satisfaction is 24.1575 .

The result shows that this tourism enterprise should first invest large costs in must-be quality elements to assure an entirely meet. It means the tourist enterprise must ensure its safety of public security and tourist facilities for protects the tourists life and the property security of the greatest degree. What's more, this tourist enterprise should fulfill the service promise accurately to ensure that tourists have sufficient time and suitable tourist route to visit the main attractions. In addition, the rest money should be for attractive quality elements to maximize customer satisfaction. It means this tourist enterprise can improve its service to bring customers pleasant surprise, for example, purchase accident insurance for all tourists, set up tourist shops and train tourist guides.

\section{Conclusions}

By analyzing the nonlinear relationship between customer satisfaction and performance of products or services, Kano model can obtain the classification of service quality elements. Traditional numeric classification is convenient but too simple, limited quantitative analysis or measurement of relationships is discussed in the traditional Kano model. This paper provides a quantitative Kano model to classify service quality elements, and an empirical study based on tourism industry application will be provided to illustrate how the proposed methodology works in practice. This paper proposes a quantitative Kano model by identifying the relationship functions between customer satisfaction and service quality elements fulfillment. Then based on the quantitative analysis in Kano model, in the context of and considering cost budget, the optimization model of improving tourism industry service quality to maximize the customer satisfaction is constructed, and the budget allocation is determined by solving the optimization model.

For some other tourism enterprise, some suggestions can be drawn from the decision method. Firstly, in order to achieve better service quality, identifying and understanding service quality elements from customer perspective is critical. Secondly, high level of service quality always with high level of costs, accounting for cost constraints in the decision making of service quality improvement is practical and functional. Thirdly, the approach proposed in this paper provides a guideline to maximize service quality, and they can make different sets of parameters to adapt to their own service contexts and practical surroundings.

Nevertheless, there are two major shortcomings, which are worth highlighting for the improvement of the existing approach. First, the function of attractive and must be quality elements are estimated by an exponential function, the validity should be demonstrated by large amounts of data. Second, this study does not consider customer's actual perception importance, which is significant to the enterprise's decision. These shortcomings will be further studied in the future.

\section{References}

[1] Kong, T., Kan, R.-L. and Mou, X.-J. (2011) Research on Service Quality Engineering Management of Tourist Destination-Taking the Yangtze Three Gorges for Example. Systems Engineering Procedia, 1, 309-316. http://dx.doi.org/10.1016/j.sepro.2011.08.047

[2] Wang, W.F., Chen, J.S., Fab, L.L. and Lu, J.Y. (2012) Tourist Experience and Wetland Parks: A Case of Zhejiang, China. Annals of Tourism Research, 39, 1763-1778. http://dx.doi.org/10.1016/j.annals.2012.05.029

[3] Coghlan, A. (2012) Facilitating Reef Tourism Management through an Innovative Importance-Performance Analysis Method. Tourism Management, 33, 767-775. http://dx.doi.org/10.1016/j.tourman.2011.08.010

[4] Chen, Y., Barry, M. and Li, Z. (2013) Quality Deterioration in Package Tours: The Interplay of Asymmetric Information and Reputation. Tourism Management, 38, 43-54.

[5] Karsak, E.E. (2004) Fuzzy Multiple Objective Decision Making Approach to Prioritize Design Requirements in Quality Function Deployment. International Journal of Production Research, 42, 3957-3974. http://dx.doi.org/10.1080/00207540410001703998

[6] Chan, L.K. and Wu, M.L. (2005) A Systematic Approach to Quality Function Deployment with a Full Illustrative Example. Omega, 33, 119-139.

[7] Kano, N., Seraku, N., Takahashi, F. and Tsuji, S. (1984) Attractive Quality and Must-Be Quality. The Journal of Japanese Society for Quality Control, 14, 147-156.

[8] Matzler, K. and Hinterhuber, H.H. (1998) How to Make Product Development Projects More Successful by Integrating 
Kano's Model of Customer Satisfaction into Quality Function Deployment. Technovation, 18, 25-38.

[9] Chen, C.C. and Chuang, M.C. (2008) Integrating the Kano Model into a Robust Design Approach to Enhance Customer Satisfaction with Product Design. International Journal of Product, 114, 667-681.

[10] Hsieh, K.L. (2009) The Application of Value Analysis Based on Kano’s Two Dimensions Model and Value Expansion Model. Information Technology Journal, 8, 1020-1026.

[11] Meng, Q.L., Zhou, N.J., Tian, J., et al. (2011) Analysis of Logistics Service Attributes Based on Quantitative Kano Model: A Case Study of Express Delivering Industries in China. Journal of Service Science and Management, 4, $42-51$.

[12] Jiao, J. and Chen, C.H. (2006) Customer Requirement Management in Product Development: A Review of Research Issues. Concurrent Engineering: Research and Applications, 14, 173-185. http://dx.doi.org/10.1177/1063293X06068357

[13] Berger, C. (1993) Kano’s Methods for Understanding Customer-Defined Quality. Center for Quality Management Journal, 2, 3-36. 